\title{
Gastrointestinal Fistula, CTCAE 5.0
}

National Cancer Institute

\section{Source}

National Cancer Institute. Gastrointestinal Fistula, CT CAE 5.0. NCI Thesaurus. Code C146637.

A disorder characterized by an abnormal communication between any part of the gastrointestinal system and another organ or anatomic site. 